\title{
Characteristics of Bus Rapid Transit Projects: An Overview
}

\author{
James T. Jarzab, Commuter Associates \\ James Lightbody and Eugene Maeda \\ Santa Clara Valley Transportation Authority
}

\begin{abstract}
During the previous century the public transit industry has struggled with mode and technology issues. Bus and rail have alternated in primacy as operating conditions and financial necessity have pressured operators to seek more cost-effective means of moving passengers. Federal, state, and local financial resources have been outstripped by candidate rapid transit projects, traffic congestion is a growing problem, and travel patterns are becoming increasingly dispersed. In seeking to fill the gap between conventional bus service and rail projects of all kinds, the transit industry in cooperation with the Federal Transit Administration (FTA) has placed renewed emphasis on the development of alternatives that reflect a return to the transportation system management approach. Equipped with new tools for improving operating and management productivity of highway and transit networks, transportation agencies are working cooperatively to simulate exclusive rights-of-way operations in mixed-traffic environments as well as meld the line-haul efficiencies of rail with the distribution flexibility of bus. These efforts are known collectively as Bus Rapid Transit (BRT), and as with any entity in its infancy, final appearances at maturity are far from certain.
\end{abstract}




\section{Introduction}

Within the last decade, the concepts of "bus service" and "rail service" have evolved with elements of their definitions blurring into a hybrid of characteristics between the two modes of transportation. In general, when one thinks of "bus" it evokes an image of a single-unit, elongated vehicle with a driver collecting fares and manually steering the rubber-tired vehicle on concrete or asphalt pavement along a predetermined route and time schedule in mixed traffic. Alternatively, the thought of "rail" produces an image of multiple-unit train cars with a conductor who has human or mechanical assistance collecting fares, and whose steering is guided by parallel tracks with the vehicle riding on steel wheels. Advancements in technology_particularly those involving Intelligent Transportation Systems (ITS) - have altered these images and mode characteristics. In combination with the growing concern of forecast population growth, land development intensification, traffic congestion, and associated pollution, communities have been looking for new and innovative approaches to address the issue of metropolitan mobility. One option that has recently been gaining attention and popularity is BRT.

BRT is the latest "buzz word" within the public transit community and has been promoted as the economic and practical solution to improving existing public transit systems. But exactly what is BRT? In initial appearance, BRT looks like a light rail system but physically operates like a bus. Although several BRT-like systems exist in North America, these systems defy easy comparison. And, while many professionals within the public transit community are familiar with or at least have heard of some of the more common characteristics of BRT and, perhaps the most-referenced BRT system, the BRT system in Curitiba, Brazil, there is still some question as to what distinguishes BRT from conventional bus systems.

During the past few years, federal, state, and local transportation agencies as well as various transportation professional associations within the United States have been collaborating to clearly define BRT for the purpose of educating the public and elected officials. This effort is essential for promoting the benefits of the BRT mode in addition to establishing criterion for funding in a very competitive environment. 


\section{Purpose}

This article observes and explores the characteristics and current applications of BRT projects as a mode of public transportation. The scope includes a comparison between BRT and light rail, a discussion on the definition and characteristics of BRT projects, and observations on current applications and effectiveness of BRT projects.

\section{Bus Versus Light Rail}

Some may find it amusing that in the discussion of bus versus rail, the respective modes have been considered superior to their counterparts during various periods of development. When first developed, rail service was a marked improvement over transportation by highway in terms of cost, comfort, speed, and reliability. Among a variety of reasons, increased traffic congestion in urban areas prompted a return to prominence for buses in the mid-20th century, but like a pendulum, declining bus service quality and urban redevelopment aspirations put rail service (now in exclusive rights-of-way) back into the spotlight. Even so, high capital and maintenance costs for rail projects have prompted a renaissance of bus-based transit projects.

Concepts commonly thought of as characterizing BRT in the United States have been discussed for over half a century. Transportation agencies in the 1950s were already looking for ways to implement a higher quality, lowercost "rail-like" transit service (California Public Utilities Commission 1957), and the limited opportunity to identify or create exclusive rights-of-way has turned this interest into ongoing explorations (Crain 1963).

Those familiar with current transit bus operations may find the phrase "BRT" a bit of an oxymoron. The reason is that the average conventional bus route in revenue service tends to operate at half the speed of general traffic when it shares rights-of-way in arterial operation. Though improvements such as "express" or "limited" services have been implemented in some fashion by almost all transit agencies, many bus routes still operate in shared right-of-way environments and are subject to the standard cycling of traffic signals. Indeed, there has been considerable effort on the part of the transit industry to move beyond bus service as the primary medium-capacity service delivery mode 
with the introduction of light rail systems, which are perceived to be less intrusive than heavy rail and yet have increased capacity and speed over bus. In addition, light rail has attractiveness as a tool for transit-oriented development, a characteristic not convincingly displayed by bus service of any type.

The federal funding category of "New Starts" has essentially been the exclusive domain of rail service since its inception. For the most part, bus operations have been relegated to the mundane workhorse of the transit industry, the "one-size-fits-all" service offered throughout the United States. Even so, the flexibility of bus also has its advantage: buses sharing rights-of-way with general traffic provide the opportunity to dedicate scarce public resources where most productive versus the high cost of initiating light rail services (U.S. Department of Transportation 1989). This is particularly the case in markets where the superior operating characteristics for multiunit consists provided by exclusive rights-of-way are not essential. The ability to maneuver around temporary obstacles offers the opportunity to maintain schedule adherence where grade separation from general traffic is not feasible. While buses can and do take advantage of exclusive right-of-way and grade separation, conceptually they provide excellent performance in mixed traffic where light rail cannot operate as effectively. Therefore, BRT may (or may not) involve the use of exclusive rights-of-way, may (or may not) involve the use of transit signal priority, and may (or may not) benefit from the use of automated vehicle identification (AVI) and/or location technologies. Regardless of the mix of features present, BRT projects are designed to operate much faster and more reliably than conventional bus transit systems (Federal Transit Administration 2001).

In a majority of instances where political necessity warrants high-capacity transit consideration (i.e., light or heavy rail), exclusive right-of-way may be unattainable (at least within any given project's available budget). With consideration toward Transportation System Management (TSM), the industry is increasingly examining means of using off-the-shelf technology to enhance the performance of transit vehicles operating in mixed traffic. The use of computer technology to increase the sophistication of traffic control devices, improve fleet management, and provide real-time passenger information has dramatically broadened the potential for optimizing bus operations, reducing operating costs, 
and adding value to the travel time spent "ridesharing" in transit vehicles. These advances provide an opportunity to change the public's perception of bus service and increase system efficiency and effectiveness in the bargain.

Bus service usually competes for commuters and other customers at a significant operating disadvantage when compared to the automobile. Stopping frequently and having to maneuver in and out of the mainstream traffic flow (which is usually occupied by drivers with little incentive to let them in), traditional intraurban bus services are perceived by the public as being too "slow and unreliable" for traveling consideration. The same circumstances affect streetcars with their restricted lateral movement in the face of obstacles. However, with enhancements, such as exclusive rights-of-way, traffic signal preemption, and a formal station, the traditional streetcar effectively becomes a light rail or rapid transit service. These advances are perceived as a hallmark of multimodal success by many metropolitan areas. To a certain extent, such a transformation is currently being applied to traditional bus service with the implementation of BRT elements.

\section{BRT Versus Light Rail Transit}

For both bus and rail services, moving transit riders with a speed and reliability comparable to that of autos has focused transportation planning and programming efforts on providing exclusive rights-of-way and/or priority traffic signals. Separating transit service from the general traffic stream has always been the preferred solution for maintaining speed and schedule adherence. Unfortunately, physical space and financial capital are rarely available to take full advantage of the benefits of exclusive rights-of-way. When both are in equal abundance, the technical choice between bus and rail is often a matter of deciding whether the travel corridor warrants high capacity at the expense of distribution flexibility and/or whether sizable segments of project right-of-way can become operational simultaneously.

Project continuity is a major issue for rail rapid transit. For obvious reasons, rail projects tend to extend from a core segment to the system maintenance facility. This core segment normally includes a central business district (CBD) with high-density residential areas that generate a substantial portion of 
the fully developed system's customer base; as such, completing this segment is essential to the successful implementation of the project. However, the very set of factors that makes the main corridor for rail services attractive (e.g., stations, park-and-ride lots, etc.) are those elements that typically involve substantial capital resources, experience significant environmental scrutiny, and are time-consuming to implement.

On the other hand, BRT projects can generally be completed in phases as funding and opportunity permit; because of service flexibility, even the core segment can be left for last. This incremental development provides an opportunity to show progress much earlier than with most rail projects. Ironically, local officials often view the flexibility of BRT service as a drawback. The "permanence" of rail right-of-way and station development is widely regarded as an irreversible public commitment to transit service capable of attracting private sector investment supportive of community development goals and objectives (Buckley and Miller 2000).

BRT on exclusive right-of-way does not markedly differ from rail rapid transit. In most applications, boarding areas are formally developed into stations complete with passenger flow control and off-vehicle fare collection. Grade separation and crossing protection from street traffic are usually provided in either instance. One of the biggest limitations of rail service versus bus service is the high cost of distributing passengers to their ultimate destinations. As experienced by many rail rapid transit operations before World War II, the expense of operating branch-line service to neighborhoods often outweighed the revenue generated for the system by those branch lines (Federal Transit Administration 1994).

In addition, the cost of maintenance for lightly used branch lines is only marginally less than that for heavily used mainlines, a fact not lost on commuter or freight railroad management. Rail transit operators rely on feeder bus services to provide this distribution, but time and financial transfer penalties dampen the attractiveness of the multiple-seat ride and foster the proliferation of park-and-ride lots. BRT operations can overcome some transfer problems by operating branch service on local streets directly to the mainline. In general, 
densely developed linear corridors with readily available exclusive rights-ofway are better suited for rail rapid transit than BRT.

In practice, it would appear that the effectiveness of BRT applications using advanced signal in mixed traffic exceeds the potential effectiveness for light rail transit (LRT) operating in the same environment. In these corridors, operating in mixed traffic may be inevitable, and mixed-traffic operation is within the domain of BRT. Given the prevailing political and financial climate, exclusive guideway operations are often out of reach of most transit agencies, even for those corridors with the heavy transit demands. Advances in automatic vehicle location (AVL) and traffic signal technology offer opportunities to reduce traffic overflowing into residential areas from the major arterial roads. The primary difficulty is not in the application of ITS; rather, the greatest problems will be encountered when structural changes required of transit organizations to effectively deploy the technology and properly market the service are implemented.

To better compete with auto vehicles for mode share, transit services should adhere to scheduled performance parameters-whether by headways or by time point - and not run ahead of schedule. In the absence of exclusive rights-of-way, transit operators are subject to the same street traffic conditions as auto drivers. While auto drivers often have the ability to adjust to delays caused by nonrecurring events (e.g., traffic accidents, fire reroutes, etc.) through route deviation, transit operators are rarely afforded that opportunity. In its effort to compensate, traditional industry practice has been to add recovery time to the schedule. Excess recovery time often results in vehicles idling or operating at a reduced speed between time points for route deviation schedule adherence, negatively impacting vehicle productivity and increasing the cost of transit operations. This simultaneously dampens demand for discretionary transit trips, adversely affecting both ridership and revenue.

The implementation of bus signal priority offers an opportunity for transit operators to maintain both competitive operating speeds and on-time performance. Traffic signal cycles can be adjusted at strategic intersections along a route to provide consistent and predictable movement for transit vehicles in 
a manner that is transparent to the public. This procedure has the potential to increase average operating speed and reduce overall travel time for transit patrons. However, signal priority alone does not guarantee on-time performance and schedule adherence. To implement these features, transit signal priority needs to be provided on a more selective basis and only activated when the transit vehicle is operating behind schedule.

Investment in exclusive right-of-ways or ITS technology does not necessarily make for a successful BRT system. Another key element to successfully implementing BRT is marketing. The purpose of marketing is to distinguish BRT from conventional bus service. The marketing for and branding of BRT appears to influence how the public, the press, and elected officials will respond to the service and future flexibility in establishing price points. In addition, size and appearance apparently does matter for BRT.

Reciting a litany echoed by customers, planners, and politicians, transit agencies want BRT buses to appear more rail-like. When translated into steered, rubber-tired transit applications, several of the vehicle designs regularly cited by transit planners and urban designers as being reflective of "raillike" characteristics are streamlined in a fashion reminiscent of art deco steam locomotives. Such bus designs have gone beyond the utilitarian "boxy" look of buses, heavy rail, and light rail vehicles generally operating in North America. Vehicles receiving a great deal of attention for BRT applications are generally articulated with smooth aerodynamic silhouettes and large windows. An example is the Civis vehicle from Irisbus of France. Domestic and foreign manufacturers currently offer or are developing similar designs.

In its final project report, Metropolitan Transportation Authority (MTA) of Los Angeles identified marketing as one of the key strategies to successfully introducing its BRT program (Metro Rapid) along Ventura and Wilshire Boulevards, two of its most heavily traveled corridors (Los Angeles Metropolitan Transportation Authority 2001, p. 18). MTA also noted the need to differentiate its Metro Rapid bus service from the other public transit modes offered. Another reason for brand marketing is to inform transit riders of the difference in service along with distinguishing BRT vehicles from the standard bus service in "look" and "feel." Specific examples are the branding and use 
of different colors schemes, operation of articulated, low-emission and/or lowfloor boarding buses, and use of electronic schedule signs and distinctive passenger shelters. Having passengers distinguish vehicles in advance of arrival reduces vehicle waiting time as passengers board and alight and minimizes potential liability exposure by encouraging orderly boarding at stops.

Like most goods and services, transit operations benefit from product differentiation. Product differentiation conveys to the public that services have been tailored to address particular travel needs. Product differentiation also allows for establishing separate service price points should the need arise. In addition, product differentiation allows ratepayers to readily perceive the investments made in services they may not regularly use or benefit from directly. Ever since public ownership became the norm in the United States, transit operators have spent considerable time and effort to standardize colors, logos, and paint schemes used on equipment and marketing material. This was particularly important during the 1970s, when changes in ownership and system consolidations were common as many transit operators were left with a mixture of equipment in varying states of repair and sporting an array of color schemes. The effort made to rationalize cost and equipment maintenance has left many transit agencies cautious when considering product differentiation.

However, advertising other products has always been a major part of transit operations. Car cards and, more recently, partial and full advertising wraps on both buses and rail vehicles have significantly altered the basic public presentation for most transit operations without adversely affecting corporate image. Across the transit industry, fixed-route service is usually distinguished from dial-a-ride by the size of vehicle, and more often than not, by the logo and service mark. Rail operations are clearly distinguished from bus by the technology.

Beyond the fact that the BRT program is expected to provide a faster, more highly reliable trip than conventional bus service, there are practical operational and political reasons to emphasize BRT's greater comfort and advanced features with the public. The difficulty encountered in conveying these service aspects largely reflects the minimal physical differentiation between service types when operating in mixed traffic. 
The public transit industry has been collaborating with the FTA in an effort to define BRT characteristics. While not exhaustive, some key characteristics of BRT systems are identified below:

- Running Ways: BRT vehicles can operate practically in any traffic environment, but the provision of limited or exclusive use can give BRT its speed, reliability, and identity. BRT running ways can be operated almost anywhere: on abandoned rail lines, within a highway median, or on city streets. A few examples are exclusive transitways, high-occupancy vehicle (HOV) lanes, dedicated transit lanes, transit streets or malls, and queue bypass lanes.

- Stations: BRT stops can be distinguished from conventional bus service by using unique station design elements. Examples of BRT station elements are real-time vehicle arrival information, streamlined passenger shelter designs, specific paint schemes, and logos.

- Vehicles: BRT vehicles can have features that improve comfort, speed, and safety (e.g., low-floor and multiple double-wide doors to allow fast and convenient boarding, wide aisles to provide ease of passenger movement, etc.) in addition to having distinctive design, color, and graphics to provide a unique identity for vehicles in BRT service.

- Service: BRT systems should provide fast, frequent, and reliable service, with stops spacing of 1 mile or more.

- Fare Collection: BRT systems typically offer fast and efficient fare collection systems to speed boarding and increase convenience.

- ITS: BRT systems generally rely on advanced digital technologies to improve customer convenience, speed, reliability, and safety. Examples of ITS elements are AVI and AVL systems, bus signal priority, and closed circuit television monitoring of operations (Transportation Research Board 2000).

Clearly, the array of features identified above need not be unique to BRT. However, because they are not yet widely available in conventional bus services, the introduction of several elements can significantly set apart BRT from other operations in a transit system. 


\section{A Sampling of BRT Projects}

High-capacity transit services in corridors with traffic volumes like those found with the Brisbane, Vancouver, and Ottawa BRT operations have historically been pursued in the United States as light rail corridors. BRT projects on exclusive rights-of-way in the Miami and Pittsburgh BRT programs are substantially influenced by the availability of abandoned freight rail lines and, at least in the case of Pittsburgh, the distinctive topography of the service area. Fully-developed stations that provide off-vehicle revenue collection opportunities and passenger flow control are a characteristic of these projects. Effectively using the resources available, distinct service types have been created that offer higher-quality "rail-like" service in a bus environment.

For many-if not most-areas aspiring to provide "rail-like" service, exclusive rights-of-way are hard to come by. The task in these cases is to provide a pseudo-rail operation in mixed traffic and to support that operation with accoutrements common to premium travel options.

For example, Los Angeles County MTA's Metro Rapid BRT service currently incorporates these BRT elements: simple route layout, frequent service, level boarding and alighting, color-coded buses, and stations. Metro Rapid does not use articulated buses or exclusive bus lanes, and yet MTA is able to significantly improve the efficiency and effectiveness in the operation as compared to parallel conventional service (Los Angeles Metropolitan Transportation Authority 2001). In a conscious effort to distinguish the BRT mode from basic bus service, BRT stops are physically separated from local bus stops.

Interestingly, the advertising slogan chosen for Los Angeles' Metro Rapid operation is "New, faster service—same fare!" Efforts have been made in public outreach sessions to emphasize that BRT in mixed traffic is the wave of the future for basic bus service. Positioning the Rapid" operation in this manner logically precludes charging a fare premium, and no fare premium is currently being considered. Additional alternatives at various corridors and facilities are being developed by the MTA and the Los Angeles Department of Transportation (LADOT), significantly extending the reach and improving the 
effectiveness of the Rapid ${ }^{\mathrm{TM}}$ service. Plans calling for future median operation in exclusive rights-of-way are in abeyance, given the success of operating improvements with bus signal priority.

MTA's Rapid concept presentation has been given a great deal of attention, with various design features displayed prominently in the branding of the service. In addition to the extensive marketing materials produced for the Rapid bus operations, the MTA corporate website presents the service on the same footing as their rail operations. MTA has used bus priority technology to minimize bus bunching and increase average operating speed. Published schedules identifying scheduled time points were eliminated and service information instead focuses on the period between bus appearances, avoiding apparent guarantees of travel time for trips.

In Ottawa, Ontario, a 19-mile transitway was implemented in stages from 1978 to 1996 . This bus-only road leads to the CBD, where it connects to exclusive bus lanes on city streets. Over 75 percent of passenger bus trips are made using the transitway. The transitway was constructed largely on rail rights-ofway and was designed for possible future conversion to rail. The main transitway routes use articulated buses with proof-of-payment fare collection to speed boarding; approximately one quarter of the riders pay cash. Feeder buses operate on a timed-transfer system (Federal Transit Administration website: http://www.fta.dot.gov/brt/projects/ottawa.html, March 9, 2002).

In Pittsburgh, the 5-mile long West Busway was constructed in an abandoned rail right-of-way that connects rapidly growing communities in the corridor between the City of Pittsburgh and Pittsburgh International Airport. The facility varies in width from two to four lanes, providing a sufficiently wide cross section to allow express buses to pass vehicles stopped at any of the busway's six stations. Fourteen bus routes use the busway; the BRT system was designed so that additional routes could be added in the future (Federal Transit Administration website: http://www.fta.dot.gov/brt/projects/pittsburgh.html, March 9, 2002).

The project also includes the Wabash HOV Facility. This 1.1-mile, reversible single-lane facility includes a tunnel through Mt. Washington, using the existing Smithfield Street Bridge to access downtown Pittsburgh. Because 
buses are able to pass other buses stopped at stations, two types of bus operations are permitted. The 100 West Busway all-stops route, similar to light rail operation, travels the length of the busway. It stops at all stations, and leaves the busway in the downtown area to provide CBD circulation. This route continues through the downtown and travels to Oakland, an educational, medical, and museum center (Federal Transit Administration website: http://www.fta.dot.gov/brt/projects/pittsburgh.html, March 9, 2002). Express commuter routes, the second type of service, enter the busway at one of a number of ramps located along the length of the facility and proceed nonstop to downtown Pittsburgh. The busway is projected to create opportunities for transit-oriented private land development at stations or other transportation hubs in the service area.

The West Busway brings the number of miles of exclusive busways operated by the Port Authority to 16.1. The 4.3-mile South Busway opened on December 18, 1977, and the 6.8-mile Martin Luther King, Jr. East Busway opened on February 21, 1983. The East Busway now carries approximately 30,000 riders on an average weekday, making it the Port Authority's most heavily used fixed-guideway facility. The West Busway carries approximately 7,000 customers per day, with ridership expected to grow upon completion of all proposed park-and-ride lots (Federal Transit Administration website: http://www.fta.dot.gov/brt/projects/pittsburgh.html, March 9, 2002).

\section{Conclusions}

Reviewing bus and rail rapid transit attributes provides an opportunity to explore the continuum available in terms of technology and its application. With regard to BRT, it need not-and should not-be perceived as a low-cost alternative to LRT. Rather, the services offered by the transit industry should be a reflection of the travel desires of the public and the financial capacity to sustain operation. Adopting a context-sensitive design approach for transit investments is more meaningful with BRT in the short list of options.

In application, BRT elements vary considerably between projects. Therefore, BRT as a mode of transportation includes many variations. By definition, it is truly "omnibus." Form follows function; whether "bus" or "rail," 
it is essential that the investments made in the name of "rapid transit" deliver real improvements to the traveling public in terms of speed, reliability, comfort, and safety.

\section{References}

Ben-Akiva, Moshe, and Takayuki Morikawa, Ridership Attraction of Rail Compared with Bus. Report prepared for Urban Mass Transportation Administration, U.S. Department of Transportation. Massachusetts Institute of Technology, 1991.

Biehler, Allen D. 1989. Exclusive Busways Versus Light Rail Transit: A Comparison of New Fixed-Guideway Systems. Report prepared for Transportation Research Board.

Buckley, S. M., and A. M. Miller. 2000. Institutional aspects of Bus Rapid Transit-A macroscopic examination. California PATH Program, Institute of Transportation Studies, University of California, Berkeley.

California Public Utilities Commission, Transportation Division, Traffic Engineering Section. 1957. Report on Bus Rapid Transit between Concord and Oakland-San Francisco. San Francisco, CA: California Public Utilities Commission.

Crain, J. L. 1963. The rapid transit bus concept. Paper. Menlo Park, CA: Stanford Research Institute.

Federal Transit Administration. 1994. The bus transit system: Its underutilized potential. Washington, DC: U.S. Department of Transportation, Federal Transit Administration.

Federal Transit Administration 1998. Bus Rapid Transit Demonstration Program. Washington, DC: United States Department of Transportation, Federal Transit Administration.

Federal Transit Administration. 1998. Issues in Bus Rapid Transit. Washington, DC: U.S. Department of Transportation, Federal Transit Administration.

Federal Transit Administration, website: http//brt.volpe.dot.gov/ issues/pt1.html, April 16, 2001.

Federal Transit Administration website: http://www.fta.dot.gov.html. March 9, 2002. 
Federal Transit Administration website: http://www.fta.dot.gov/brt/projects/ottawa.html, March 9, 2002.

Federal Transit Administration website: http://www.fta.dot.gov/brt/ projects/pittsburgh.html, March 9, 2002.

General Accounting Office. 2001. Report to Congressional Requesters: Mass Transit-Bus Rapid Transit Shows Promise. Washington, DC: U.S. General Accounting Office.

Levine, L. 2000. Bus Rapid Transit Duels with Rail. Metro, pp. 43-44.

Los Angeles Metropolitan Transportation Authority. 2001. Los Angeles. Metro rapid demonstration program final report. Los Angeles: Los Angeles Metropolitan Transportation Authority.

Mitretek Systems. April 2001. Bus Rapid Transit Vehicle Characteristics (Draft). Washington, DC: Federal Transit Administration.

Pushkarev, B. S., and J. M. Zupan. 1977. Public Transportation and Land Use Policy. Canada: Indiana University Press.

Schiemek, P. April 16, 2001. Bus Rapid Transit: Reference Guide. Federal Transit Administration website. http://brt.volpe.dot.gov/guide/index.html.

Transportation Research Board. 2000. Bus Rapid Transit: Why more communities are choosing Bus Rapid Transit.

U.S. Department of Transportation. 1989. Urban rail transit projects: Forecast versus actual ridership and costs. Cambridge, MA: Transportation Systems Center.

Vuchic, V. R. 1999. Transportation for Livable Cities. New Brunswick: Center for Urban Policy Research.

\section{About the Authors}

JAMES T. JARZAB (commuterassociates@yahoo.com) is president and principal of Commuter Associates. Currently BRT program manager for the Santa Clara Valley Transportation Authority (VTA), his 30 years of professional experience is divided between transit and regional planning. Prior to entering private practice, Mr. Jarzab managed strategic and policy planning for Pace, the suburban bus division of Chicago's Regional Transportation Authority. In serving this position, his responsibilities included long-range 
planning, transportation demand management, market research, and transitoriented development. Mr. Jarzab attended Bradley and Illinois State Universities receiving, respectively, B.S. and M.S. degrees in economics.

JAMES LiGHTBODY (lightbody@ vta.org) is deputy director of transit planning and development for VTA. His responsibilities include management of transit studies associated with the development of new transportation services and facilities, planning for transit-oriented development, and the direction of the authority's capital grants and financial planning efforts. He has been with VTA for more than 30 years, with management positions in transportation planning and transit operations. Mr. Lightbody received engineering degrees from Santa Clara and Stanford Universities.

Eugene S. MAEDA (eugene.maeda@vta.org) is a transportation planner with VTA. He has nearly 10 years of professional experience and is currently working on the Downtown/East Valley major investment study. Prior to joining VTA, Mr. Maeda worked in the express freight transportation industry with ground operations and operations management. He is currently pursuing an M.S. in urban and regional planning at San Jose State University and holds a B.S. degree in transportation management from San Francisco State University. 